\title{
Title: Outgroup Threat and the Emergence of Cohesive Groups: A Cross-Cultural Examination
}

Lang, M. ${ }^{{ }^{*},}$, Xygalatas, D. ${ }^{2}$, Kavanagh, C.M. ${ }^{3,4}$, Boccardi, N. ${ }^{5}$, Halberstadt, J. ${ }^{6}$, Jackson, Ch. ${ }^{6}$, Martínez, M. ${ }^{7}$, Reddish, P. ${ }^{8}$, Tong, E. M. W. ${ }^{8}$, Vazquez, A. ${ }^{7}$, Whitehouse, H. ${ }^{4}$, Yamamoto, M. E.

${ }^{5}$, Yuki, M. ${ }^{4}$, \& Gomez, A. ${ }^{7,9}$

\section{Affiliations:}

${ }^{1}$ LEVYNA: Laboratory for the Experimental Research of Religion, Masaryk University, Czech Republic

${ }^{2}$ Department of Anthropology, University of Connecticut, USA

${ }^{3}$ Department of Behavioral Science, Hokkaido University, Japan

${ }^{4}$ Centre for the Study of Social Cohesion, Oxford University, United Kingdom

${ }^{5}$ Department of Psychobiology, Federal University of Rio Grande do Norte, Brazil

${ }^{6}$ Department of Psychology, University of Otago, New Zealand

${ }^{7}$ Department of Psychology, Universidad Nacional de Educación a Distancia, UNED

${ }^{8}$ Department of Psychology, National University of Singapore, Singapore

${ }^{9}$ ARTIS International, Spain

*Correspondence to: $\underline{\text { martinlang@mail.muni.cz }}$ 


\begin{abstract}
Evolutionary models and empirical evidence suggest that outgroup threat is one of the strongest factors inducing group cohesion, however, little is known about the process of forming such cohesive groups. We investigated how outgroup threat galvanizes individuals to affiliate with others to form engaged units that are willing to act on behalf of their in-group. A total of 864 participants from six countries were randomly assigned to an outgroup threat, environmental threat, or no-threat condition. We measured the process of group formation through physical proximity and movement mirroring together with activity toward threat resolution and found that outgroup threat induced activity and heightened mirroring in males. We also observed higher mirroring and proximity in participants who perceived the outgroup threat as a real danger, albeit the latter results were imprecisely estimated. Together, these findings help understand how sharing subtle behavioral cues influences collaborative aggregation of people under threat.
\end{abstract}

Key words: Activity; Cohesion; Mirroring; Outgroup threat; Proximity; Willingness to fight

Abstract word count: 151

Main text word count: 9230

References word count: 2114

Tables word count: 507

Tables and figures: three tables and two figures 


\section{Introduction}

Intergroup conflict is a pervasive problem in human societies and affects the lives of millions around the world. Despite international diplomacy handling conflicts at the nation-state level, grassroots movements of active individuals often rise up to protect parochial sacred values in the face of outgroup threat, as exhibited in various protest movements, public militias, suicide terrorists, and other embattled communities (Atran \& Ginges, 2012; Newson et al., 2018). Through self-organized assortment into cohesive groups, individuals strongly committed to their brothers in arms, nation, ethnicity, and/or religion are willing to take costly actons against outgroups (Glowacki et al., 2016).

Evolutionary models suggest that human psychology has been molded by a long history of fierce intergroup conflict (Bowles, 2008) and predict that increased outgroup threat will produce higher rates of parochial altruism (Bowles, 2009; Whitehouse et al., 2017), that is, prosocial behaviors confined only to in-group members. Experimental studies conducted in areas with recent histories of intergroup conflict indicate that such violent conflict translates into heightened progroup behavior and increased fairness during within-group interactions in children and early adolescents (Bauer, Cassar, Chytilová, \& Henrich, 2014; Voors et al., 2012). More broadly, intergroup competition is associated with increased public-goods contributions to the in-group (Francois, Fujiwara, \& Ypersele, 2018; Majolo \& Maréchal, 2017). Furthermore, a combination of ethnographic and historical evidence indicates that during intergroup competition, groups endorse tighter norms (Gelfand, 2019; Gelfand et al., 2011) and costlier forms of ritual behavior that signal norm adherence (Sosis, Kress, \& Boster, 2007). These and other commitment signals (e.g. increasing similarity and proximity) may serve as mechanisms to maintain or reinforce coalitional safety in the face of an outgroup threat (Boyer, Firat, \& van Leeuwen, 2015).

At the psychological level, threatening a group's values incentivizes individuals to express willingness to fight for their group (Atran, 2016) and to protect their values at all costs (Ginges \& Atran, 2011). Such behaviors often take the form of pro-active harm to outgroups as illustrated by observational studies of sports fans (Newson et al., 2018; Wann, Carlson, \& Schrader, 1999), experiments using economic games (De Dreu, Dussel, \& Ten Velden, 2015; De Dreu et al., 2016), and experiments manipulating closeness to the victims of the $9 / 11$ terrorist attack in the USA (Dumont, Yzerbyt, Wigboldus, \& Gordijn, 2003). The effect of outgroup threat on willingness to 
act is especially strong in individuals whose identity is "fused" with their group identity (Gómez et al., 2011, 2017): in a series of laboratory studies, participants scoring higher on identity fusion (a visceral feeling of oneness with the group) expressed increased willingness to fight or die for their country (Gómez et al., 2011; Swann, Gómez, Seyle, Morales, \& Huici, 2009). Furthermore, a field study of Libyan soldiers showed that on a forced-choice question, almost half of front-line combatants chose fellow fighters rather than family as their primary fusion target (Whitehouse, McQuinn, Buhrmester, \& Swann, 2014). On the basis of such results and a decade of research on identity fusion (e.g. Gómez et al., 2020), Whitehouse (2018) has proposed a "general theory of extreme self-sacrifice" which posits a relationship between identity fusion and willingness to engage in extreme self-sacrifice for a group that is moderated by perceptions of threat. As briefly described, there is preliminary evidence in support of this theoretical model, but much stronger empirical tests are necessary to examine the proposed relationships.

Together, evolutionary models and empirical evidence suggest that intergroup conflict is positively correlated with group cohesion and pro-group behavior, and that such behavior increases a group's survival and success in intergroup competition. However, little is known about the process of forming such cohesive groups under threats from antagonistic groups. In other words, what are the low-level dynamic processes that guide interpersonal interactions between anonymous individuals to come together to defend a common identity against outgroups? While group support through verbal commitment is often necessary, behavioral nonverbal cues are generally more reliable signals of group commitment and willingness to fight (Fessler \& Holbrook, 2014; Sosis et al., 2007; Tracy, Randles, \& Steckler, 2015) and reflect the dynamics of group formation. In the present study, we aimed to develop novel measurements of these behavioral cues (for a review of previous approaches see Salas, Grossman, Hughes, \& Coultas, 2015) and examine their dynamics under external threat. To this end, we followed Carron and Brawley (2000) and identified two key behavioral cues that reflect the dynamic process of group formation: increasing willingness of group members to affiliate with each other in the face of danger and pursuing the group's defensive goals through instrumental action.

Regarding non-verbal behavioral cues of affiliative tendencies, previous research has long recognized two crucial mechanisms: movement mimicry and physical proximity. Movement mimicry is defined as adopting behavioral patterns, postures, and mannerism of interaction 
patterns, often automatically and without conscious processing (Lakin, Jefferis, Cheng, \& Chartrand, 2003). Importantly, heightened mirroring increases liking, rapport, empathy, and prosociality among anonymous individuals (for a review see Duffy \& Chartrand, 2015) and signals romantic interests in other people (Farley, 2014; Karremans \& Verwijmeren, 2008). In teams, movement mimicry reflects group alignment from the motor to the intentional level (Hasson \& Frith, 2016) whereby mimicry facilitates effective team communication and collaboration (Zhang, Olenick, Chang, Kozlowski, \& Hung, 2018). Testing the relationship between movement mimicry and team cooperation, postural mimicry has been shown to correlate with student engagement in college seminars (Lafrance \& Broadbent, 1976) and artificially manipulating mimicry between teachers and students affected the rating of their rapport (Bernieri, 1988). Moreover, a study of six crew members deployed on a four-month simulation of space exploration mission revealed that movement mimicry was positively correlated with reported group cohesion in their daily tasks (Zhang et al., 2018).

Proximity, on the other hand, is defined as physical interpersonal closeness (Allen, 1970; Cook, 1970). While a related concept to movement mimicry, proximity captures different aspects of social rapport, specifically, the preference to engage in trust-based interaction and face-to-face communication (with one extreme end being dyadic intimate relationships). By allowing others to frequently share the same physical location, individuals may exchange key information and share emotionally charged experiences (Hoegl \& Proserpio, 2004), which are crucial in bonding people together (Whitehouse \& Lanman, 2014). A study of 145 software developer teams in Germany revealed that physical proximity was correlated with self-reported teamwork quality, including the cohesion of each team (Hoegl \& Proserpio, 2004) and similar results were obtained in the study of 67 nurses in a Boston area hospital (Olguin Olguin, 2011). Crucially, physical proximity was shown to be a reliable indicator of within-group cohesion and liking (Jackson et al., 2018) and priming with interdependent/social constructs of self similarly produced higher interpersonal proximity (Holland, Roeder, Van Baaren, Brandt, \& Hannover, 2004). Note that we do not claim that being in close proximity is always beneficial for a group; rather, we understand it as an opposition to individual dispersal and an indicator of interpersonal liking. In our conceptualization, both mimicry and proximity are automated behavioral patterns that reflect the dynamical process of group emergence through affiliative tendencies. 
Apart from building social rapport through mimicry and proximity, Carron and Brawley (2000) identified a group's ability to self-organize and act in the face of danger as another important component contributing to group functioning. Focusing on instrumental activity related to an outgroup threat, previous research showed that threat from antagonistic groups positively affects self-declared willingness to act and even sacrifice for the group (Gómez et al., 2017; Swann et al., 2009) and an ability to effectively organize for group defense (Böhm, Rusch, \& Gürerk, 2016; De Dreu et al., 2016). However, while relevant to our current question, these studies do not capture the automated dynamical process of group building but reflect a one-shot conscious decision. In everyday situations, the group-building enterprise often requires specific physical action (such as helping with labor, coordinating in defense) to benefit others rather than direct financial costs (Lockwood et al., 2017); in other words, physical action and related energy expenditure dedicated to solving a group problem might better reflect the dynamic process of building functioning groups. Indeed, average daily movement energy was shown to correlate with self-reported creativity of research teams tracked over a two-week period (Tripathi \& Burleson, 2012) and movement energy was another crucial predictor of perceived team cohesion in the studies of Boston nurses (Olguin Olguin, 2011) and simulated space exploration mission (Zhang et al., 2018) described above.

Based on the review of these automated group-building processes, we should expect that the presence of an outgroup threat should trigger affiliative behaviors (proximity and mirroring) and behaviors directed toward conflict resolution (physical effort). To investigate this hypothesis, we sampled 864 participants in six different countries. See Tab. 1 for the list of countries and SM for detailed description of field sites. To provide cross-cultural robustness for our results, these countries were selected to represent diverse and geographically distant cultures from five continents and six dominant languages.

In each of our field sites, we randomly assigned participants to either an outgroup threat, environmental threat, or nonthreatening condition (approx. 45 participants per condition in each country) and used innovative and unobtrusive methods to quantify the effects of these conditions on emergent behavioral properties that indicate group formation. Specifically, groups of four same-sex participants read an article about an upcoming international conference addressing either the threat posed by the ISIS terrorist group (outgroup-threat experimental condition), the threat 
posed by an earthquake (environmental-threat control condition), or vaguely specified "international politics" (no-threat baseline condition). Following this manipulation, participants were instructed to make a group decision during a 20-minute discussion period on which three delegates (from among six potential candidates differing in their endorsement of parochial and national politics) should represent their country at the conference. To quantify the individual progroup behavioral patterns during the 20-minute discussion period, we employed Sociometric Badges (Kim, Mcfee, Olguin, Waber, \& Pentland, 2012; Waber et al., 2011). These devices collected individual-level data on physical activity, the extent of mirroring the movements of the other three participants in the experimental session as well as physical proximity to those participants. These unobtrusive and continuously collected measures of mirroring, proximity, and activity revealed the dynamics of spontaneous behavior that is not necessarily consciously reflected and may be too subtle to afford video-coding, thus inaccessible to typical psychometric and social psychology methods. On top of these main outcome variables, we also asked participants about their willingness to fight for their country. See Fig. 1 for the raw distribution and cross-cultural variation of the outcome variables.

Building on evidence that socio-political and environmental threats promote coordinated collective action (Gelfand, 2019; Gelfand et al., 2011), we hypothesized that both threat conditions (outgroup and environmental) would increase participants' affiliative behaviors and activity compared to the no-threat baseline condition. Furthermore, we predicted that there would be a greater willingness to fight for one's country in the outgroup threat condition compared to the nothreat baseline condition. Besides these main models, we tested three additional hypotheses related specifically to our manipulation of outgroup threat. First, since intergroup conflict, coalitional aggression, and warfare have been historically and cross-culturally dominated by males (McDonald, Navarrete, \& Van Vugt, 2012; Yuki \& Yokota, 2009), we hypothesized that males will display more affiliative behaviors and activity in the outgroup threat condition compared to the no-threat baseline condition. We did not expect such a difference between the environmental and baseline conditions. Second, since individuals sites differed in their appraisal of threat posed by international terrorism, we hypothesized that higher sensitivity to such threats should moderate the effects of our treatment such that mirroring, proximity, and activity would be stronger in the outgroup treatment compared to the baseline condition. Finally, based on the identity fusion theory, we hypothesized that the effects of identity fusion with one's country on increasing 
participants' affiliative and instrumental behaviors would be stronger in the outgroup threat condition compared to the baseline condition, with no difference between the environmental and baseline conditions (see SM for additional predictions). 

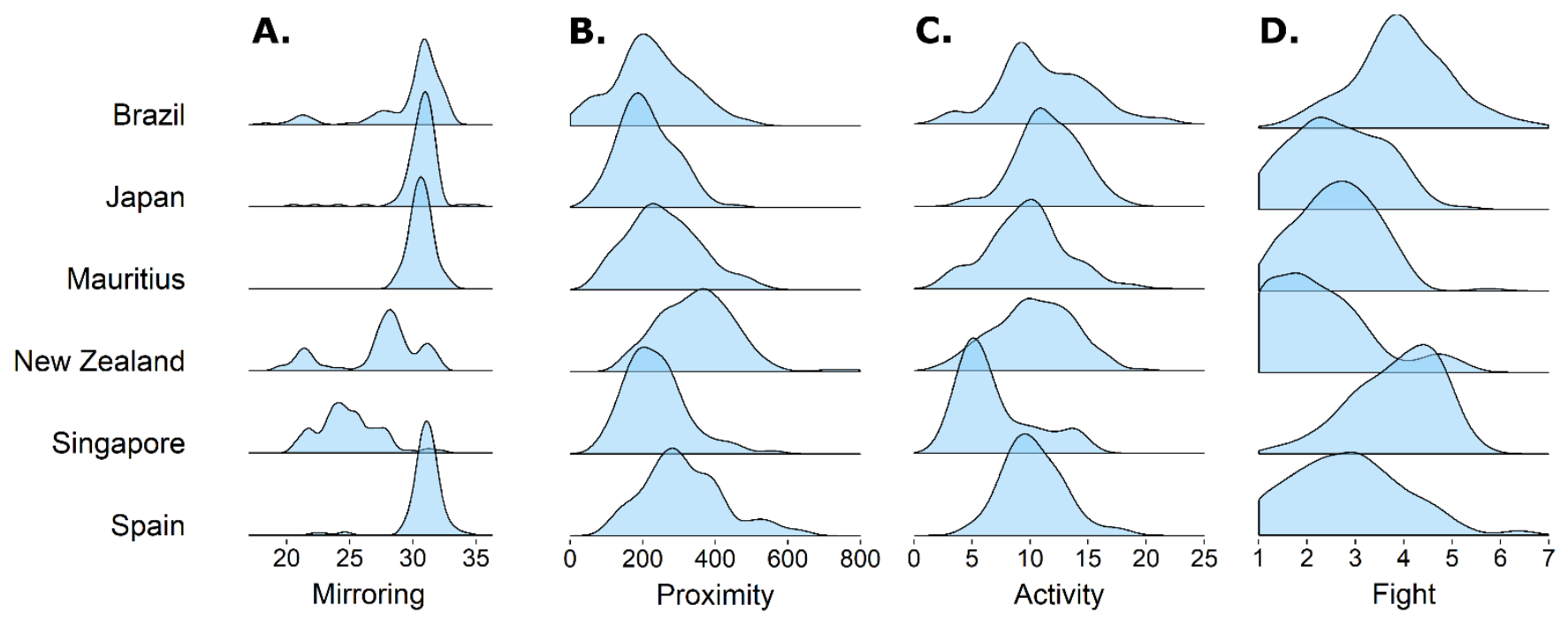

Fig. 1. Density Plots of our Four Dependent Variables.

Tab. 1. Averages with SD of Demographic Variables.

\begin{tabular}{lccccc}
\hline \hline Site & $\mathrm{N}$ & Females & Age & Terrorism & World Risk \\
\hline Brazil & 144 & 82 & $23.3(4.2)$ & 1.572 & $4.23 \%$ \\
Japan & 136 & 72 & $19.9(1.2)$ & 3.595 & $13.47 \%$ \\
Mauritius & 172 & 88 & $21.3(1.9)$ & 0 & $15.11 \%$ \\
New Zealand & 144 & 92 & $21.1(6.3)$ & 0.611 & $4.42 \%$ \\
Singapore & 116 & 92 & $20.9(1.4)$ & 0 & $2.36 \%$ \\
Spain & 152 & 84 & $32.3(8.3)$ & 1.701 & $3.23 \%$ \\
\hline Total/Grand M & 864 & 510 & $23.3(6.4)$ & 1.247 & $7.14 \%$ \\
\hline \hline
\end{tabular}

Note. Terrorism is the Global Terrorism Index (GTI) in 2016, ranging from 0 to 10. World Risk Index (WRI) showing 2016 data is a score computing exposure and institutional vulnerability to natural disasters. See SM, section S1.2 for site details. 


\section{Methods}

\subsection{Participants}

Data collection took place in six countries: Brazil, Japan, Mauritius, New Zealand, Singapore, and Spain over a period of two years (2015-2016). In each country, we recruited university students in groups of four, 864 participants in total (510 females; Mage $=23.3, \mathrm{SD}=6.4$ ). We excluded 33 participants whose native language did not correspond to the study site; 12 participants who did not fill out questionnaires; and 77 participants from the analysis of sociometric data due to the malfunctions of the Sociometric Badge. All procedures were approved by the Institutional Review Board at the University of Connecticut, and additional approval was obtained in all countries where an ethics committee was locally available. See Supplementary Material, section S2 for additional information about specific sites.

\subsection{Procedure and Materials}

For each testing, five participants of the same sex were invited to a laboratory, with one participant serving as a surrogate. In the cases when all five participants arrived, the surrogate participant was paid a show-up fee (except for Brazil where rules did not allow payment for research participation) and did not take part in the experiment. We standardized the laboratory rooms across our sites to include four cubicles with computers, a desk in the middle of the room for group discussion, two desks by opposite walls with various tools, and a white board (see Fig. S1). Each experiment was conducted by a research assistant who was blind to our hypotheses.

Upon arrival to the study site, participants were fit with Sociometric Badges that had visible subject numbers and each participant was instructed to sit in a cubicle matching their badge number. In the first part of the experiment, participants filled out questionnaires assessing identity fusion with their country and demographic variables. Subsequently, each group was randomly assigned to one of three conditions: an outgroup threat condition, an environmental threat condition, and a no-threat baseline condition. Participants were given six minutes to read closely an article detailing an upcoming conference on one of the three topics: the threat of the Islamic State of Iraq and the Levant (ISIS; outgroup threat condition), an unspecified earthquake disaster (environmental threat condition), and generic international cooperation (baseline condition). The texts in all three conditions were identical except for one paragraph detailing the potential threat; and each text was anchored by a relevant picture: an ISIS soldier with a knife and a hostage kneeling in front of him in the outgroup threat condition; a girl amid debris following an 
environmental disaster in the environmental threat condition; and a generic conference picture in the baseline condition. See Supplementary Material, section S5 for all prime materials. Note that the content of all primes was identical across our field sites to assure between-site comparability of the obtained results. While the risk for the outgroup and disaster threats naturally varies across the field sites, we conducted additional robustness analyses to account for this variation (see below).

After reading the priming texts with anchoring pictures, participants were asked to answer questions about the content of the article to ensure they paid sufficient attention (we control for mistakes during attention check in our statistical models) as well as to remind them of the main topic of the conference (they were asked to describe the image and the main topic of the conference). Following this attention check, participants were collectively (i.e., in their groups of four) introduced to a modified version of the Hidden Profile task (Stasser \& Titus, 2003), which is a form of group-decision task where some information is shared collectively while some is accessible only to certain members of the group. In the present experiment, each participant received an information sheet at their cubicle with six candidates that might negotiate on behalf of the participants' country at the upcoming conference (introduced in the priming material). Each sheet comprised six characters with three statements for each candidate: two statements were shared among all participants and one statement was unique for each participant (based on the Hidden Profile paradigm). Participants were then given three minutes to study the information. The candidates were defined based on two variables: a) their degree of parochialism (based on statements of in-group devotion/outgroup hostility) and b) whether they had a military or civilian background. See Supplementary Material, section S6 for candidate materials. After reading the materials, participants were instructed to get together in the middle of the room to discuss and decide on which candidate should represent their country at the upcoming conference with the condition-specific topic (ISIS threat; earthquake; control topic). At the end of the 20-minute period, participants were asked to have completed the following tasks: 1) attach printed symbols of three selected candidates to the whiteboard and 2) create a 'poster' providing at least one reason from each participant, which indicated the rationale for selecting the specific candidates. The 20minute hidden profile interaction task was the primary measurement period for our sociometric data; the task was designed to encourage dynamic movement and regrouping, providing raw material for our behavioral measures. 
Following the Hidden Profile task, participants were asked to leave the experimental room and wait in a hallway adjacent to the room until the experimenter called them back. This fiveminute period was intended to allow us to assess our main measures of interest during a free interaction period rather than during a structured task. Finally, the experimenter called participants back into the room, asking them to fill out final questionnaires that assessed their willingness to fight, die, and make other costly sacrifices on behalf of their country. At the end of the experiment, participants received either class credit or a show-up fee paid at standard rates for an hour-long experiment in each location (except for Brazil, where participants were not allowed to receive money per national policy).

\subsection{Measures}

Our measures were divided into survey items and behavioral measures obtained through the Sociometric Badges. While the behavioral measures comprised our outcome variables, the survey measures comprised both outcome variables (willingness to fight) as well as predictor and control variables (e.g., identity fusion, conflict salience).

\subsubsection{Surveys}

All materials were translated and then back-translated into each site's local language to ensure comprehension. Questionnaires were presented through the computer program Qualtrics, except in Mauritius, where we used pen and paper. Before creating latent variables out of individual scale items, we assessed measurement invariance of the theoretical constructs across our sites (Boer, Hanke, \& He, 2018). Specifically, we used multi-group confirmatory factor analysis (MG CFA; Muthén, 1989) to test for configural, metric, and scalar invariance (using R code developed by Fischer \& Karl, 2019). For each invariance test, we obtained basic fit indices, assessed the model fit (well-fitting models indicated by CFI and TLI > .95; RMSEA < .06; SRMR < .08; Vandenberg $\&$ Lance, 2000) as well as the difference between the fit of the invariance models ( $\triangle \mathrm{CFI}<-0.02$; L. Rutkowski \& Svetina, 2014).

First, we created a latent variable pertaining to willingness to fight for one's country (Swann, Gómez, Huici, Morales, \& Hixon, 2010) measured with a five-item scale. Since the model revealed metric variance, we removed one item which improved the overall fit of the configural model as well as metric invariance $(\mathrm{CFI}=0.99, \mathrm{TLI}=0.97, \mathrm{RMSEA}=0.05$, and $\mathrm{SRMR}=0.02$; see Tab. S3 for loadings and intercepts by country). However, we also detected scalar variance 
$\left(\Delta C F I_{\text {scalar-metric }}=-0.81\right)$, which was driven by the Japanese site. We provide two remedies for the detected scalar variance - first, we let the intercepts for the willingness to fight vary between sites (see below), effectively focusing on the within-site variance in this measure. Second, in the SM, we provide the same analyses excluding the Japanese site.

Similarly, we analyzed the invariance of pre-existing levels of participants' fusion with their country, which served as a moderating factor in our models. Fusion with country was measured using the seven-item fusion scale developed by Swann et al. (2009), which was previously tested in various countries (Swann et al., 2014) and its visual analogue predicted cooperation in small-scale societies (Purzycki \& Lang, 2019). After eliminating two items that increased metric variance, the configural invariance model revealed a sufficient fit to the data (CFI $=0.95, \mathrm{TLI}=0.89, \mathrm{RMSEA}=0.15$, and SRMR $=0.04$; see Tab. S3 for loadings and intercepts by country). To account for detected scalar invariance, we z-scored the identity fusion measure by site such that the differential distribution of this predictor variable across sites would be taken into account. See SM, section S1.2 for further discussion of the MG CFA analysis.

As another potential factor moderating the effects of our treatment on group formation, we obtained participants' assessments of the threat posed to their country by international conflict to account for the fact that our sites differed in their potential exposure conflict (answered on a 7point Likert scale from "strongly disagree" to "strongly agree"). As control variables, we collected data on the Ten Item Personality Measure (TIPI; Gosling, Rentfrow, \& Swann, 2003) to assess extraversion and neuroticism. Since this measure is not meant to capture a single latent concept, we did not expect that the configural, metric, and scalar invariance should hold (see Supplementary $\mathrm{R}$ code for details). Instead, we used only two items ("I see myself as anxious, easily upset"; "I see myself as extraverted, enthusiastic") to assess the individual levels of neuroticism and extraversion, which may affect the behavioral measures (Olguin Olguin, 2011). Furthermore, we asked participants to place themselves on a liberal-conservative political spectrum using a 7-point Likert scale (from "very liberal" to "very conservative") and how much they perceive earthquakes threaten their country (from "strongly disagree" to "strongly agree"). We also asked participants whether they have met any of the other participants from their session before the experiment and control for this potential familiarity in our statistical models (in 18\% of sessions at least two people knew each other; however, removing these sessions from the regression models did not change 
our results - see Supplementary R code). To ensure that participants paid attention to our manipulation, we asked participants three control question (year and name of the conference, participating countries) and use the number of mistakes to adjust the coefficients in our statistical models. Finally, we asked participants to rate the credibility of the provided article to control for the inter-individual variability in the prime's effectiveness. See SM, section S4 for the full questionnaire.

\subsubsection{Behavioral measures}

To obtain continuous behavioral measures during the Hidden Profile task and the free-interaction period, we employed the Sociometric Badge (Kim, Mcfee, Olguin, Waber, \& Pentland, 2012; Waber et al., 2011). This badge is of similar size to a common smartphone (although much lighter) and is placed on the chest, hanging on a lanyard placed around the neck. Each badge records activity through an accelerometer, computed as the absolute value of the first derivative of energy (see Fig. S2 for an illustration). For easier interpretation, we multiplied the activity values by 9.8 to get acceleration in $\mathrm{m} / \mathrm{s} 2$. Thus, difference in activity means both difference in the vigor and frequency of activity. Note that to make sure that this activity did not rather reflect coping with a common threat or reluctance to associate with others (e.g., walking far from the group), we control for neuroticism and introversion in our supplementary analyses.

Furthermore, each badge sends Bluetooth signals to other badges with a frequency of $1 \mathrm{~Hz}$ and measures the strength of the signal reciprocated by other badges that are within interaction proximity (Received Signal Strength Indicator - RSSI). The strength of the returned signal is thus a measure of relative distance between two badges (independent of whether participants faced each other or not). Since the RSSI measure is indicated in negative numbers of $\mathrm{dB}$ with $-90 \mathrm{~dB}$ being the detection threshold (around 1.5 meters) and $0 \mathrm{~dB}$ the maximal proximity, we transformed the RSSI such that 0 is the detection threshold and 90 the maximal signal strength. This transformation affords intuitive reading of proximity with increasing positive numbers indicating increasing proximity. See Fig. S3 for an illustration. The proximity score for each participant is computed as a sum of RSSI values of all detected interactions with the other three participants in the same session and divided by the number of minutes for each task to arrive at average proximity per minute. Similar to activity, the sum of RSSI values subsumes both the temporal and spatial dimension to account for the fact that some participants may have had less frequent but very close encounters. Since one proximal encounter is counted for both individuals in proximity (irrespective 
of who was the approaching individual), the number of these interactions is to some extent sessionspecific. That is, while each participant has a unique proximity score reflecting their interaction with other three participants, these scores are to some extent correlated between participants in one session. We adjust our regression models for this overlap in encounters by letting the intercepts for individual sessions to vary; that is, by fitting a session-specific intercept and analyzing only the variance not explained by this intercept (see Analysis section and SM, section S3 for the amount of variance explained by varying intercepts by session; see also Supplementary R code).

Finally, by combining the accelerometer measurements with proximity values and detection of face-to-face interactions (via infrared sensors), the Sociometric Badge provides measurements of movement mirroring. When two participants are in close encounter (defined by the proximity measurement) and faced each other, the badge compares their activity levels: utilizing a five-second sliding window, the percentage of mirrored movements is computed for each second. Thus, the value of movement mirroring corresponds to an average percent of movements mirrored between participants in a group during our tasks. Similar to proximity, the mirroring measure reflects a dyadic encounter and is, therefore, counted for both individuals (imitator and imitatee). The overlap of the movement mirroring measure between participants in one session should be again absorbed by letting the intercepts of our regression models to vary by session.

Note that the number of participants differ between the survey and sociometric models, reflecting failures of memory cards in the Sociometric Badges and similar technical difficulties. Site-specific means and standard deviations for outcome and predictor variables are displayed in Tab. S1 and S2, respectively. All sociometric data were extracted using the Sociometric DataLab software, version 3.1.2468.

\subsection{Analysis}

The data were analyzed in R, version 3.4.1 (R Core Team, 2020). Each model is a hierarchical linear model with three levels: participants nested within sessions that are nested within sites. First, we nested participants within sessions (each session comprised four participants) to account for the fact that individual-level measures are correlated between participants from the same session. Second, since our data set comprised data from six different countries, we treat country-specific means as varying intercepts in all our models, controlling for baseline between-site differences in 
our outcome variables (i.e., intercept differences) and other potential unmeasured between-site variability. Together, this hierarchical structure allowed us to investigate individual-level predictors of mirroring, proximity, activity, and willingness to fight while accounting for the interdependencies within our data. We set the no-threat baseline condition as the reference category, displaying the differences between the baseline and outgroup threat conditions, and the baseline and environmental conditions, respectively.

As a starting point, we built linear mixed models (LMMs) examining the main effects of our manipulation (outgroup threat, environmental threat, and baseline conditions). In the second step, we added individual characteristics, adjusting our models for the potentially confounding effects of sex, identity fusion, salience of international conflict, salience of natural disaster, extraversion, neuroticism, and conservatism. In the third step, we adjusted our models for variables assessing the quality of our manipulation, namely participants' rating of the credibility of our priming material, the number of wrong answers during the attention check, and whether participants knew someone else in their session. The general model structure was as follows:

$$
Y_{i}=\left(\left(\beta_{0 i}+u_{0 j}+u_{0 k}\right)+T_{1 i} \beta_{1}+T_{2 i} \beta_{2}+X_{i} \beta_{3}+Z_{i} \beta_{4}+\varepsilon_{i}\right) \sim N\left(\mu, \sigma^{2}\right)
$$

where $Y_{i}$ is our behavioral measure of individual $i$ within session $j$ and site $k . \beta_{0}$ is a fixed intercept, $u_{0 j}$ is a varying intercept for session and $u_{0 k}$ is a varying intercept for site. $T_{1 i} \beta_{1}$ is the individuallevel parameter for the fixed effect of outgroup threat treatment (no-threat baseline vs. outgroup threat) and $T_{1 i} \beta_{2}$ is the individual-level parameter for the fixed effect of environmental threat treatment (no-threat baseline vs. environmental threat). $X_{i} \beta_{3}$ is the group of individual-level parameters for the effects of sex, identity fusion, salience of international conflict, salience of natural disaster, extraversion, neuroticism, and conservatism. $Z_{i} \beta_{4}$ is the group of individual-level parameters for the effects of participants' rating of the credibility of our priming material, the number of wrong answers during attention check, and whether participants knew someone else from their session. $\varepsilon$ represents the error term for the assumed normal distribution.

After examining these models, we interacted the treatment factor variable with three types of theoretically important moderators: sex, the salience of international conflict, and identity fusion. Next, we performed four robustness checks: 1) instead of LMMs, we fitted generalized linear mixed-models (GLMMs) that allowed us to more rigorously account for the specific datageneration process of our outcome variables; 2) we built the same LMMs as in our main analyses 
but excluded the New Zealand site that had multiple nationalities in the sample; 3) we analyzed group formation also during the free-interaction task that followed immediately after the Hidden Profiles task; and 4) let the slopes of credibility of our primes, salience of international conflict, salience of natural disaster, and individual conservatism to vary by site to account for the variables' potentially different effects across sites. For details on these robustness checks and packages used in the analysis see Supplementary Material, section S1.3 and Supplementary R code. Note that for the sake of brevity, we show only the core findings in the main text while full models with all controls can be found in Supplementary Material, section S3.

\section{Results}

\subsection{Manipulation Check}

As a manipulation check, both the outgroup threat $(\beta$-estimate $=1.49,95 \% \mathrm{CI}=[1.21-1.78])$ and environmental threat $(\beta$-estimate $=1.52,95 \% \mathrm{CI}=[1.23-1.81])$ conditions increased the feeling of being threatened to a similar level compared to the no-threat baseline condition. However, only in the outgroup threat condition $(\beta$-estimate $=0.31,95 \% \mathrm{CI}=[0.05-0.58])$ and not in the environmental threat condition $(\beta$-estimate $=-0.02,95 \% \mathrm{CI}=[-0.28-0.24])$ participants were more likely to elect more parochial candidates compared to the baseline condition (for more details and other checks see Supplementary Material, section S3.1). These manipulation checks suggest that our manipulation successfully elicited threatening feelings, which were, nonetheless, specific to particular threats.

\subsection{Main Models}

First, when participants were in face-to-face contact, we observed that on average about $28 \%$ of their movements within the 5-sec moving window were mirrored in the no-threat baseline condition. While the amount of mirroring in the outgroup threat condition did not differ from the baseline condition $(\beta$-estimate $=-0.06,95 \% \mathrm{CI}=[-0.69-0.58])$, we observed higher movement mirroring in the environmental threat condition $(\beta$-estimate $=0.71,95 \% \mathrm{CI}=[0.07-1.35])$.

Next, the differences between the baseline and outgroup and environmental conditions in the measure of proximity varied around zero (see Tab. 2). Regressing participants' activity (indicated as a mean acceleration per second) on the experimental conditions, the LMM revealed that participants were more active in both the outgroup threat $(\beta=0.74,95 \% \mathrm{CI}=[-0.08-1.55])$ 
and environmental conditions $(\beta=0.82,95 \% \mathrm{CI}=[0.005-1.64])$ compared to the no-threat baseline condition, albeit the $95 \%$ CI for the outgroup threat condition crossed zero.

Finally, we observed the highest willingness to fight for one's country in the outgroupthreat condition $(\beta=0.13,95 \% \mathrm{CI}=[-0.05-0.30])$, albeit the 95\% CI again crossed zero. The difference between the baseline no-threat condition and environmental condition revealed larger variability $(\beta=0.07,95 \% \mathrm{CI}=[-0.11-0.25])$. Excluding the Japanese sample from the analysis of willingness to fight (see Methods/Materials) strengthened these results ( $\beta_{\text {outgroup }}=0.20,95 \% \mathrm{CI}$ $\left.=[0.00-0.41] ; \beta_{\text {environmental }}=0.08,95 \% \mathrm{CI}=[-0.12-0.29]\right)$.

These results were robust toward adding a set of theoretically important predictors as well as adding a set of variables related to the experimental manipulation. Furthermore, we also let the slopes of these control variables to vary by site and conducted analyses with different distributional assumptions for the residuals. None of these robustness checks suggested that the reported relationships are unstable. See Table 2 and Supplementary Material, section S3 for detailed results of each modelling step and further discussion as well as for site-specific analyses.

\begin{tabular}{|c|c|c|c|c|}
\hline & Mirroring & Proximity & Activity & Fight \\
\hline Treatment: Outgroup & $\begin{array}{c}-0.06 \\
(-0.69,0.58)\end{array}$ & $\begin{array}{c}-4.72 \\
(-30.01,20.58)\end{array}$ & $\begin{array}{c}0.74 \uparrow \\
(-0.08,1.55)\end{array}$ & $\begin{array}{c}0.13 \\
(-0.05,0.30)\end{array}$ \\
\hline Treatment: Environmental & $\begin{array}{c}0.71^{*} \\
(0.07,1.35)\end{array}$ & $\begin{array}{c}-4.39 \\
(-29.76,20.99)\end{array}$ & $\begin{array}{c}0.82 \dagger \\
(0.005,1.64)\end{array}$ & $\begin{array}{c}0.07 \\
(-0.11,0.25)\end{array}$ \\
\hline Intercept & $\begin{array}{c}28.82 * * * \\
(26.87,30.77) \\
\end{array}$ & $\begin{array}{c}267.93 * * * \\
(221.34,314.51) \\
\end{array}$ & $\begin{array}{c}9.53 * * * \\
(8.07,10.99) \\
\end{array}$ & $\begin{array}{c}2.96 * * * \\
(2.38,3.54) \\
\end{array}$ \\
\hline N Participants & 761 & 762 & 761 & 824 \\
\hline
\end{tabular}

\subsection{Interaction Models}

\subsubsection{Sex as a moderator}

Investigating the moderating role of sex on mirroring, we observed that the difference between sexes in the outgroup threat condition was larger compared to the no-threat baseline condition; specifically, for each 5-sec window, males mirrored each other movements $1 \%$ more than females in the outgroup threat condition $\left(\beta_{\text {difference }}=1.38,95 \% \mathrm{CI}=[0.06-2.71]\right)$. There was no interaction effect between sex and the environmental threat condition $\left(\beta_{\text {difference }}=-0.02,95 \% \mathrm{CI}=[-1.32-\right.$ 
1.28]). A post-hoc analysis of simple effects from the interaction model revealed that males in the outgroup condition displayed higher mirroring rates than males in the baseline condition, although confidence intervals of this effect showed high uncertainty $\left(\beta_{\text {outgroup, } \text { males }}=0.70,95 \% \mathrm{CI}=[-0.23\right.$ - 1.62]). Furthermore, the absence of the interaction effect in the environmental condition was likely caused by a lower intercept for mirroring in the outgroup condition (i.e., lower mirroring rates observed in females in the outgroup condition compared to females in the baseline condition, see the intercept differences in Tab. 3).

For proximity, we did not observe the moderating sex effect: males were generally lower in proximity, but this difference did not vary across our manipulation (see Tab. 3 and Fig. 2). Looking at the moderating role of sex on activity, we observed on average 1.47 times faster accelerations for male activity compared to females when participants faced the outgroup threat, and this sex difference was higher compared to the sex effect in the no-threat baseline condition $\left(\beta_{\text {difference }}=2.04,95 \% \mathrm{CI}=[0.37-3.71]\right)$. As predicted, the sex effect did not differ between the environmental and baseline conditions $\left(\beta_{\text {difference }}=0.56,95 \% \mathrm{CI}=[-1.08-2.21]\right)$. A post-hoc analysis revealed that compared to males in the baseline condition, males in the outgroup condition were more active $\left(\beta_{\text {outgroup, males }}=1.81,95 \% \mathrm{CI}=[0.42-3.20]\right)$. See Fig. 2 and Tab. 3.

\subsubsection{Conflict salience as a moderator}

Focusing on the moderating effects of conflict salience, we observed that the slope of conflict salience predicting the amount of mirroring was more positive in the outgroup condition compared to the no-threat baseline condition $\left(\beta_{\text {difference }}=0.20,95 \% \mathrm{CI}=[-0.01-0.40]\right)$ while the slopes of the environmental and baseline conditions were indistinguishable $\left(\beta_{\text {difference }}=0.09,95 \% \mathrm{CI}=[-\right.$ $0.12-0.29])$. A post-hoc analysis of these interaction effects showed that participants scoring highest on the conflict salience scale displayed higher mirroring rates compared to the similarly scoring participants in the baseline condition $\left(\beta_{\text {outgroup, conflict salience }>6}=1.67,95 \% \mathrm{CI}=[-0.02-\right.$ 3.37]). However, analogically to the moderating effects of sex on mirroring, this interaction effect was driven mostly by low mirroring rates of participants with low conflict salience scores in the outgroup condition (see the intercept differences in Tab. 3).

Conflict salience also showed important moderating effects for our measures of proximity. In the no-threat baseline condition, increasing conflict salience was associated with decreasing proximity but the opposite trend was observed in the outgroup threat condition $\left(\beta_{\text {difference }}=9.67\right.$; 
95\% CI $=[0.45-18.88])$. No such slope difference was observed between the no-threat baseline and environmental threat conditions $\left(\beta_{\text {difference }}=1.81,95 \% \mathrm{CI}=[-7.26-10.88]\right)$. However, while the post-hoc analysis of the interaction effect for the outgroup condition revealed that the effects for participants scoring highest on this latent variable in the outgroup condition indeed showed highest mirroring rates from all of the comparison groups, the difference from the baseline condition was quite variable and does not allow us to draw confident inferences $\left(\beta_{\text {outgroup, conflict }}\right.$ salience $>6=17.71,95 \% \mathrm{CI}=[-37.10-72.53])$. Possibly, the significant interaction for the outgroup condition is partially driven by the fact that participants who were not worried about international conflict were lower in proximity in the outgroup threat condition compared to the no-threat baseline (see intercepts of this model in Tab. 3). There was no moderating effect of conflict salience for the effects of treatment on activity.

\subsubsection{Identity fusion as a mediator}

For our measure of identity fusion with one's country, the $95 \%$ CI of the moderating effects on mirroring, proximity, and activity always crossed zero. While the moderating effects for the outgroup condition were positive (as predicted), the moderating effects of identity fusion were too variable to afford unequivocal interpretation (see Tab. 3 and Fig. 2). Supplementary Material, section S3 offers further details on the interaction analyses, including the set of robustness checks as for our main models. 

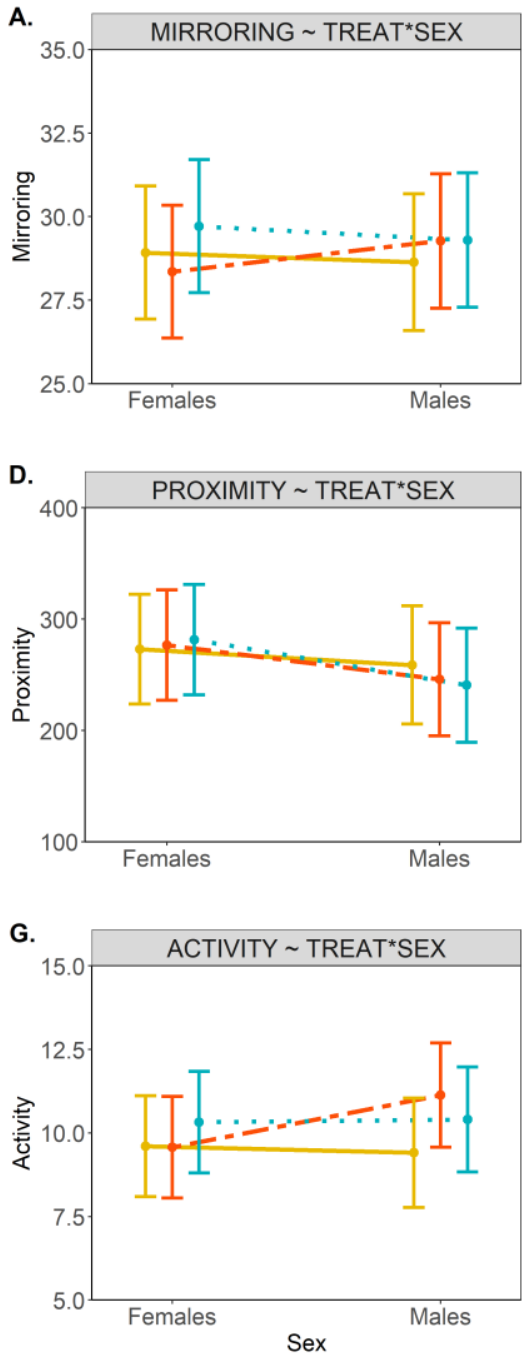

B.

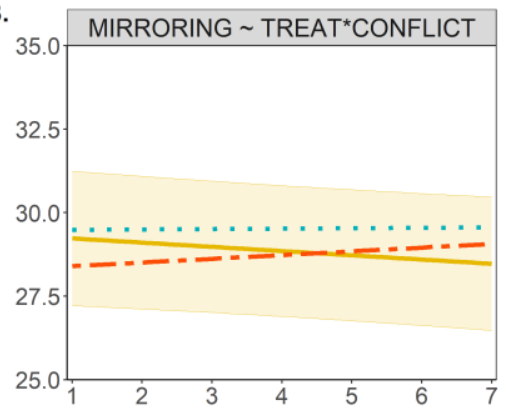

E.

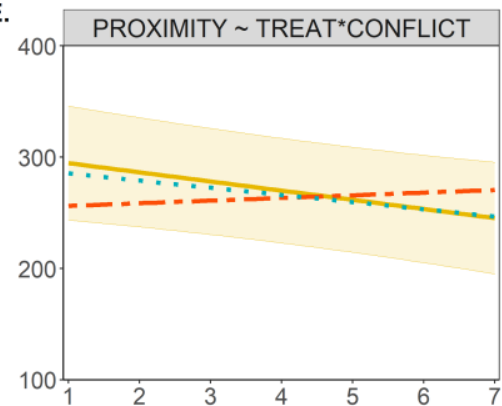

H.

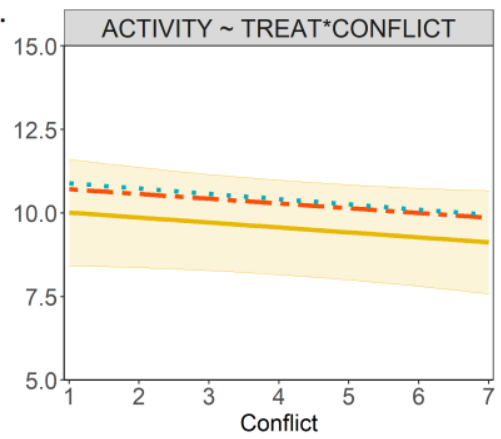

- Baseline - - Outgroup .. Enviro

C.

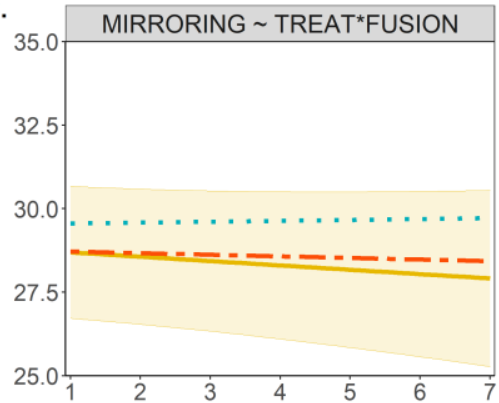

F.

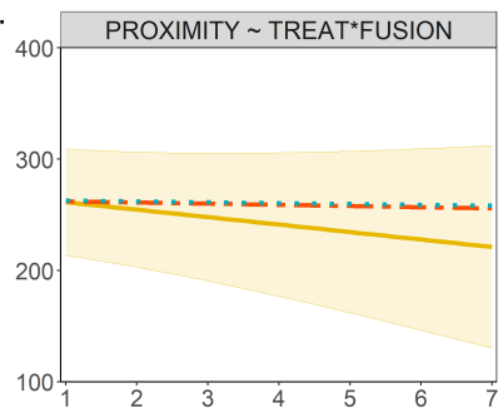

I.

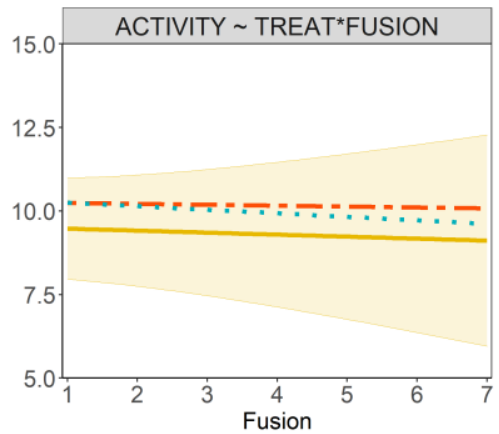

Fig. 2. A $3 \times 3$ Mesh of the Interaction Models Showing Regression Estimates with $95 \% \mathrm{Cl}$ for the No-Threat Baseline Condition. Plots show simple interactions effects adjusted only for participants' nesting in sessions and sites. Mirroring was on average higher in both threat conditions. The only stable effect on proximity was observed for participants in the outgroup condition who worried about international conflict. The activity measure displayed in the last row was on average higher in the outgroup and environmental threat conditions compared to the no-threat baseline condition, but the effect in the outgroup threat condition was moderated by sex. 
Tab 3. Beta-Estimates with $95 \% \mathrm{Cl}$ for the Interaction of Treatment with Sex, International Conflict Salience, and Fusion.

\begin{tabular}{|c|c|c|c|c|c|c|c|c|c|}
\hline & \multicolumn{3}{|c|}{ Moderator: Sex } & \multicolumn{3}{|c|}{ Moderator: Conflict Salience } & \multicolumn{3}{|c|}{ Moderator: Identity Fusion } \\
\hline & Mirroring & Proximity & Activity & Mirroring & Proximity & Activity & Mirroring & Proximity & Activity \\
\hline Treat: Outgroup & $\begin{array}{c}-0.73 \dagger \\
(-1.58,0.12)\end{array}$ & $\begin{array}{c}3.88 \\
(-29.64,37.39)\end{array}$ & $\begin{array}{c}-0.18 \\
(-1.25,0.90)\end{array}$ & $\begin{array}{c}-0.97 \dagger \\
(-2.07,0.13)\end{array}$ & $\begin{array}{c}-43.51 \dagger \\
(-89.81,2.80)\end{array}$ & $\begin{array}{c}0.60 \\
(-0.99,2.19)\end{array}$ & $\begin{array}{c}-0.15 \\
(-0.81,0.51)\end{array}$ & $\begin{array}{c}-3.00 \\
(-28.59,22.59)\end{array}$ & $\begin{array}{c}0.68 \\
(-0.16,1.51)\end{array}$ \\
\hline Treat: Enviro & $\begin{array}{c}0.67 \\
(-0.18,1.51)\end{array}$ & $\begin{array}{c}1.31 \\
(-31.93,34.54)\end{array}$ & $\begin{array}{c}0.66 \\
(-0.41,1.72)\end{array}$ & $\begin{array}{c}0.26 \\
(-0.84,1.36)\end{array}$ & $\begin{array}{c}-12.42 \\
(-58.69,33.85)\end{array}$ & $\begin{array}{c}1.10 \\
(-0.49,2.69)\end{array}$ & $\begin{array}{c}0.63 \dagger \\
(-0.02,1.28)\end{array}$ & $\begin{array}{c}-5.10 \\
(-30.39,20.20)\end{array}$ & $\begin{array}{c}0.85^{*} \\
(0.03,1.68)\end{array}$ \\
\hline Moderator & $\begin{array}{c}-0.34 \\
(-1.32,0.64)\end{array}$ & $\begin{array}{c}-22.00 \\
(-60.48,16.49)\end{array}$ & $\begin{array}{c}-0.57 \\
(-1.80,0.66)\end{array}$ & $\begin{array}{c}-0.09 \\
(-0.25,0.06)\end{array}$ & $\begin{array}{c}-9.02 * \\
(-15.91,-2.12)\end{array}$ & $\begin{array}{c}-0.12 \\
(-0.36,0.13)\end{array}$ & $\begin{array}{c}-0.20 \\
(-0.47,0.07)\end{array}$ & $\begin{array}{c}-6.91 \\
(-18.92,5.09)\end{array}$ & $\begin{array}{c}-0.10 \\
(-0.52,0.32)\end{array}$ \\
\hline Outgroup*Mod & $\begin{array}{c}1.38^{*} \\
(0.06,2.71)\end{array}$ & $\begin{array}{c}-17.05 \\
(-69.25,35.16)\end{array}$ & $\begin{array}{c}2.04^{*} \\
(0.37,3.71)\end{array}$ & $\begin{array}{c}0.20 \dagger \\
(-0.01,0.40)\end{array}$ & $\begin{array}{c}9.67^{*} \\
(0.45,18.88)\end{array}$ & $\begin{array}{c}0.02 \\
(-0.31,0.34)\end{array}$ & $\begin{array}{c}0.15 \\
(-0.23,0.52)\end{array}$ & $\begin{array}{c}5.96 \\
(-10.62,22.55)\end{array}$ & $\begin{array}{c}0.05 \\
(-0.53,0.63)\end{array}$ \\
\hline Enviro*Mod & $\begin{array}{c}-0.02 \\
(-1.32,1.28)\end{array}$ & $\begin{array}{c}-15.99 \\
(-67.25,35.27)\end{array}$ & $\begin{array}{c}0.56 \\
(-1.08,2.21)\end{array}$ & $\begin{array}{c}0.09 \\
(-0.12,0.29)\end{array}$ & $\begin{array}{c}1.81 \\
(-7.26,10.88)\end{array}$ & $\begin{array}{c}-0.06 \\
(-0.38,0.26)\end{array}$ & $\begin{array}{c}0.19 \\
(-0.18,0.55)\end{array}$ & $\begin{array}{c}8.72 \\
(-7.49,24.94)\end{array}$ & $\begin{array}{c}-0.04 \\
(-0.61,0.52)\end{array}$ \\
\hline Intercept & $\begin{array}{c}27.96 * * * \\
(25.69,30.23)\end{array}$ & $\begin{array}{c}309.32 * * * \\
(239.52,379.11)\end{array}$ & $\begin{array}{c}9.03^{* * *} \\
(6.78,11.29)\end{array}$ & $\begin{array}{c}28.12^{* * *} \\
(25.83,30.41)\end{array}$ & $\begin{array}{c}327.08^{* * *} \\
(254.97,399.19)\end{array}$ & $\begin{array}{c}8.57^{* * *} \\
(6.24,10.90) \\
\end{array}$ & $\begin{array}{c}27.77^{* * *} \\
(25.52,30.01)\end{array}$ & $\begin{array}{c}314.23^{* * *} \\
(245.62,382.84)\end{array}$ & $\begin{array}{c}8.64 * * * \\
(6.44,10.84) \\
\end{array}$ \\
\hline N Participants & 691 & 692 & 691 & 691 & 692 & 691 & 691 & 692 & 691 \\
\hline
\end{tabular}

Note: Abbreviated results from our full moderator models. The full models adjust for sex, fusion, conflict salience, natural disaster salience, extraversion, neuroticism,

conservatism, prime credibility, mistakes, and acquittance. See Tabs. S5, S11 and S16. The no-threat baseline condition is the reference category for the treatment variable.

Interactions compare the slopes of moderating variables (Moderator) across the outgroup and environmental threat conditions with the no-threat baseline condition. Treat $=$

Treatment; Outgroup = Outgroup threat; Enviro = Environmental threat.

$+p<.1 ; *<.05 ; * * p<.01 ; * * * p<.001$ 


\section{Discussion}

The current study aimed to investigate behavioral processes that affect the forming of cohesive groups under various threats. Across six diverse societies, we assessed how outgroup and environmental threats affect group dynamics by utilizing unobtrusive devices that quantify between-subject movement mirroring, proximity, and individual activity. We found that both type of threats increased activity aimed at the threat resolution, however, this effect was the strongest for males in the outgroup threat condition. Likewise, willingness to fight for one's country was strongest in the outgroup threat condition. The measures of affiliative behavior revealed more complex patterns: we observed higher mirroring rates in the environmental condition compared to the baseline condition, but the outgroup threat increased movement mirroring only for males, suggesting that females were galvanized only by the environmental threat (albeit this sex difference was imprecisely estimated). Similarly, the treatment with outgroup threat increased mirroring for people who perceived armed conflict with another country as a real threat. There were no main effects of either threat on proximity, although, similar to mirroring, participants who considered international conflict as a real threat to their country tended to spend more time in proximity in the outgroup threat condition. However, this result was substantially variable and does not afford confident inferences. We discuss these results in detail.

First, per our conceptualization of cohesive groups, we focused on two distinct facets of affiliative behavior, namely movement mirroring and proximity, and hypothesized that they will increase with outgroup threat. Both are well-established measures of interpersonal rapport (Grahe \& Bernieri, 1999; Lakin et al., 2003; Tickle-Degnen \& Rosenthal, 1990) and may be recruited as behavioral strategies to increase interpersonal liking (Bernieri, Gillis, Davis, \& Grahe, 1996; Lakin \& Chartrand, 2003) and facilitate team cohesion during instrumental tasks (Hoegl \& Proserpio, 2004; Olguin Olguin, 2011; Zhang et al., 2018). While proximity expresses mutual attraction and willingness to interact, movement mirroring is a more dynamic measure that results from actual ongoing interaction (Tickle-Degnen \& Rosenthal, 1990) and is well correlated with instrumental and helping behavior (Chartrand \& Lakin, 2013; van Baaren, Holland, Kawakami, \& van Knippenberg, 2004).

We did not observe any main effects of the threat conditions on proximity. Possibly, the Hidden Profile task constrained participants to interact within a relatively narrow distance (group 
discussion was concentrated around a table in the center of the room), masking the expected effects of our threat manipulation (Zhang et al., 2018). A stronger signal was detected in the measure of movement mirroring, which does not rely on the variance in spatial distance and is more indicative of interpersonal rapport during instrumental tasks (Tickle-Degnen \& Rosenthal, 1990; Zhang et al., 2018). Specifically, participants in the environmental threat group mirrored each other more compared the no-threat baseline condition. However, no such effect was observed for the outgroup threat condition, and we suspected that the absence of the effect in the outgroup threat condition on affiliative behaviors may be masked by the theoretically important moderators we set out to explore.

First, interacting the rating of conflict salience with our manipulation revealed that participants who were more worried about the possibility that their country will engage in an international conflict displayed higher levels of movement mirroring in the outgroup threat condition compared to the baseline condition. Since the interaction between condition and salience of international conflict in predicting the affiliative behaviors holds also after controlling for neuroticism (see Tab. S5 and S11), it is most likely not driven by affiliative tendencies of anxious individuals (Schachter, 1959). On the contrary, we suggest that the affiliative tendencies observed in the mirroring measure reflect processes of building a cohesive team by aligning group intentions and coordinating communication as well as increasing rapport, that is, factors needed for successful teamwork (Hasson \& Frith, 2016). The fact that this process was observed only for people worried about conflict supports the notion that perceived intergroup competition increases the need for within-group cooperation and increased affiliation (Francois et al., 2018; Majolo \& Maréchal, 2017). We also observed similar results for the proximity measure where conflict salience positively predicted proximity only in the outgroup condition. However, due to reasons discussed in the previous paragraph, these results were uncertain and do not afford confident interpretation.

We also observed that participants who were not worried about international conflict were lower in proximity and movement mirroring in the outgroup threat condition compared to the nothreat baseline (see intercepts of this model in Tab. 3). This finding suggests that outgroup threats may lead to the dispersal of less worried participants, possibly due to the increased importance of avoidant strategies (Ein-Dor, Mikulincer, \& Shaver, 2011). In other words, priming participants 
with outgroup threat who are usually not worried about such threats may have decreased their need for sociality. However, this interpretation is quite speculative and future research should investigate this relationship.

Second, we found that males were more sensitive to our outgroup threat manipulation. While environmental threat increased movement mirroring for both sexes, the outgroup threat increased mirroring only for males. This result is consistent with the male warrior hypothesis, which states that men are more sensitive to the cues of intergroup conflict than women (Van Vugt, De Cremer, \& Janssen, 2007) and upon the detection of such cues display higher rates of parochial cooperation (McDonald et al., 2012; Yuki \& Yokota, 2009). In light of this theory, our results might be interpreted as supporting the notion that threats increase the need for affiliation and cooperative behavior (Gelfand, 2019; Gelfand et al., 2011) with the caveat that women are less sensitive to outgroup threats and/or are unwilling to form cohesive groups under such threats. The latter notion is supported by the fact that women in the outgroup threat condition displayed even lower mirroring rates than women in the baseline condition. Nevertheless, due to the imprecise estimate of this effect (95\% CI crossed zero), this result should be interpreted with caution and investigated by future studies.

The male warrior hypothesis is further supported by our results of the activity measurement. Analogically to the mirroring results, the analysis of movement energy revealed that both threatening conditions increased participants' activity compared to the baseline condition; however, the outgroup threat increased activity only for males. In contrast to the mirroring results, women in the outgroup threat condition showed similar activity levels as women in the baseline condition, supporting the notion that the decrease in female mirroring described in the previous paragraph may have been a chance result. Furthermore, males in the outgroup threat condition showed even higher rates of activity than participants in the environmental threat condition (see Fig. 2). This result suggests that males may be hypersensitive to the cues of intergroup conflict, which is reflected in their physical action and related energy expenditure dedicated to solving a group problem as in the Hidden Profiles task. Since movement energy is correlated with perception of increased effectiveness of teamwork (Olguin Olguin, 2011), males were mobilized in the outgroup threat condition to take action, which also contributes to building cohesive groups (Zhang et al., 2018). 
The extent to which threat manipulation affected the self-reported willingness to fight for one's country was lower than we expected. While the outgroup threat condition revealed higher ratings of willingness to fight compared to the baseline condition, the $95 \% \mathrm{CI}$ for this difference crossed zero. Excluding the Japanese sample from our analysis increased this effect (see Methods for rationale), yet the detected effect remained relatively small. Nevertheless, this effect shows that our manipulation affected both self-reported and behavioral measures aimed at conflict resolution. In our supplementary analyses, we also observed a substantial sex effect with males more willing to fight (consistent with the male-warrior hypothesis), while the salience of international conflict also positively predicted willingness to fight. However, these variables did not moderate the effect of the outgroup condition (see Tab. S22).

Likewise, we did not detect any interaction between sex and outgroup threat affecting the proximity measure. Males were on average further apart from each other, but this effect was constant across all conditions. While mirroring and activity do not require physical proximity to establish rapport and facilitate collective action in males, it can be speculated that proximity is a type of affiliative behavior favored by females rather than males. The absence of a moderating effect of conflict salience on our measure of activity is likely due to the fact that activity in the outgroup and environmental threat conditions was already higher compared to the no-threat baseline condition. Finally, our measure of identity fusion with one's country did not moderate any of the treatment effects on our behavioral variables, despite the fact that previous studies showed a positive correlation between identity fusion and cooperative behavior (Purzycki \& Lang, 2019), and theoretical work predicted that this relationship should strengthen during intergroup conflict (Whitehouse, 2018).

Together, these results indicate that outgroup threat prompts active group behavior particularly for men and to some extent also increases affiliative behaviors for men and for individuals who experience the threat as a real danger to their country. To bolster these results, we performed several robustness checks reported in the Supplementary Material and our regression models include various variables that served to adjust the tested relationships. Specifically, we adjusted the models for sensitivity to threats unrelated to an outgroup threat (natural disaster) as well as for neuroticism to eliminate the variance explained by general sensitivity to threats that may provoke affiliative behaviors (Schachter, 1959; Taylor, 2006). We also adjusted the models 
for 1) participants' self-placement on the political spectrum to gauge the effects of individual conservatism and associated norm tightness (Gelfand et al., 2011); 2) individual extraversion, which may positively affect affiliative behaviors (Duffy \& Chartrand, 2015b); 3) the strength of our manipulation and attention paid to that manipulation; and, given that this was a group study, 4) for the familiarity of participants within the group.

Furthermore, by letting the intercepts vary across sites in our models, we adjusted the model estimates for the fact that the measured outcome variables were differentially distributed across our sites (see Fig. 1). To gauge the extent of between-site variation in the tested relationships, we also provide site-specific results for the main models in the supplementary material (SM, section S3). The site-specific results suggest that our manipulation usually affected the outcome variables in the same direction across the six sites, although the magnitude of those effects was variable. The only exception was the measure of proximity where the direction of coefficients related to our manipulation varied between sites, suggesting that proximity may be a measure most sensitive to the specific cultural milieu and associated conventions regarding interpersonal space (Talhelm, Zhang, \& Oishi, 2018). Finally, since our sites may have potentially differed in the extent that individuals are sensitive to various threats, we also built LMMs where we let the slopes of conflict salience, natural disaster salience, conservatism, and credibility of our manipulation on the outcome variables to vary by site. Nevertheless, the variation explained by these varying slopes was usually negligible and did not affect the interpretation of the fixed factors in our models (see SM, section S3).

Despite these various control measures, our results have important limitations. While the strength of our study lies in using a large-cross cultural sample, this sample was comprised only of student populations. Furthermore, our New Zealand sample was somewhat multi-national, which may have impacted both our behavioral and self-reported measures directed at creating cohesive groups in order to defend one's country. While excluding these international participants from our analyses and supplementary analyses without the New Zealand site did not result in any qualitative differences (see SM, section S3), future studies manipulating nation-level perception of intergroup conflict should carefully select nationally homogenous populations. Likewise, our composite measures of identity fusion and willingness to fight revealed measurement variance across sites. We improved the invariance of these latent variables by excluding items that had 
variable factor loadings across our sites, but such a practice runs into the risk of underrepresenting the concept (Fischer \& Karl, 2019).

Furthermore, whereas using the same priming materials across different field-sites confers multiple advantages, their strength and effectiveness might have been too low at sites that never experienced a terrorist attack. Combining locally salient materials that would be comparable across sites should overcome these issues, although finding such materials would be extremely challenging. Finally, while providing unique unobtrusive measurements, the Sociometric Badges often malfunctioned (we lost around 10\% of data) and require increased stability for reliable data collection, especially if such devices should be deployed in demanding real-life social situations (Xygalatas et al., 2019). Despite these limitations, our findings offer preliminary evidence of dynamic processes of bottom-up formation of groups of people who feel threatened by other groups. 


\section{Funding:}

This study was funded by a sub-grant awarded by Oxford University as part of the Ritual's Impact on the Contemporary World project, funded by the Templeton Foundation. A.G. acknowledges funding by Ministerio de Ciencia, Innovación y Universidades from the Spanish Government [RTI2018-093550-B-100].

\section{Competing Interests:}

We declare no competing interests.

\section{Data and Materials Availability:}

All data, materials, and R code are available at https://osf.io/fwztr/.

\section{Acknowledgments:}

We thank Joey Chua, Nethy Chunwan, Laura Meunier, Mehreen Mey, Avishkar Soonea, and Maneesha Soonea who helped collect data. We would also like to thank Gabriela Baranowski

Pinto, Radek Kundt, Radim Chvaja, Vitor Profeta, and members of the Culture, Cognition, and Coevolution Lab at Harvard University for providing feedback on earlier versions of this manuscript. We are also grateful to Ronald Fischer for providing statistical advice.

\section{Author Contributions:}

C.K., M.L., D.X., H.W., and A.G. conceived the study, prepared protocols, and managed data collection. N.B., J.H., C.J., C.K., M.L., M.M.D., P.R., E.T., A.V., H.W., M.E.Y., and M.Y. collected data. M.L. conducted all analyses and made graphs and tables. C.K. prepared all illustrations and materials. M.L. drafted the manuscript and supplementary material. All authors participated in refining the protocols and experimental designs and in manuscript preparation. 


\section{References:}

Allen, T. J. (1970). Communication networks in R\&D laboratories. $R \&$ D Management, $1(1)$, 14-21. https://doi.org/10.1017/CBO9781107415324.004

Atran, S. (2016). The devoted actor: Unconditional commitment and intractable conflict across cultures. Current Anthropology, 57(S13), S192-S203. https://doi.org/10.1086/685495

Atran, S., \& Ginges, J. (2012). Religious and sacred imperatives in human conflict. Science, 336(6083), 855-857. https://doi.org/10.1126/science.1216902

Bauer, M., Cassar, A., Chytilová, J., \& Henrich, J. (2014). War's enduring effects on the development of egalitarian motivations and in-group biases. Psychological Science, 25(1), 47-57. https://doi.org/10.1177/0956797613493444

Bernieri, F. J. (1988). Coordinated movement and rapport in teacher-student interactions. Journal of Nonverbal Behavior, 12(2), 120-138. https://doi.org/10.1007/BF00986930

Bernieri, F. J., Gillis, J. S., Davis, J. M., \& Grahe, J. E. (1996). Dyad rapport and the accuracy of its judgment across situations: A lens model analysis. Journal of Personality and Social Psychology, 71(1), 110-129.

Boer, D., Hanke, K., \& He, J. (2018). On detecting systematic measurement error in crosscultural Research: A review and critical reflection on equivalence and invariance tests. Journal of Cross-Cultural Psychology, 49(5), 713-734. https://doi.org/10.1177/0022022117749042

Böhm, R., Rusch, H., \& Gürerk, Ö. (2016). What makes people go to war? Defensive intentions motivate retaliatory and preemptive intergroup aggression. Evolution and Human Behavior, 37(1), 29-34. https://doi.org/10.1016/j.evolhumbehav.2015.06.005

Bowles, S. (2008). Conflict: Altruism's midwife. Nature, 456(20), 326-327. https://doi.org/https://doi.org/10.1038/456326a

Bowles, S. (2009). Did warfare among ancestral hunter-gatherers affect the evolution of human social behaviors? Science, 324, 1293-1298. https://doi.org/10.1126/science.1168112 
Boyer, P., Firat, R., \& van Leeuwen, F. (2015). Safety, threat, and stress in intergroup relations: A coalitional index model. Perspectives on Psychological Science, 10(4), 434-450. https://doi.org/10.1177/1745691615583133

Carron, A. V., \& Brawley, L. R. (2000). Cohesion: Conceptual and measurement issues. Small Group Research, 31(1), 89-106.

Chartrand, T. L., \& Lakin, J. L. (2013). The antecedents and consequences of human behavioral mimicry. Annual Review of Psychology, 64, 285-308. https://doi.org/10.1146/annurevpsych-113011-143754

Cook, M. (1970). Experiments on orientation and proxemics. Human Relations, 23(1), 61-76. https://doi.org/10.1177/001872677002300107

De Dreu, C. K. W., Dussel, D. B., \& Ten Velden, F. S. (2015). In intergroup conflict, selfsacrifice is stronger among pro-social individuals, and parochial altruism emerges especially among cognitively taxed individuals. Frontiers in Psychology, 6(572), 1-9. https://doi.org/10.3389/fpsyg.2015.00572

De Dreu, C. K. W., Gross, J., Méder, Z., Giffin, M., Prochazkova, E., Krikeb, J., \& Columbus, S. (2016). In-group defense, out-group aggression, and coordination failures in intergroup conflict. Proceedings of the National Academy of Sciences, 113(38), 10524-10529. https://doi.org/10.1073/pnas.1605115113

Duffy, K. A., \& Chartrand, T. L. (2015a). Mimicry: causes and consequences. Current Opinion in Behavioral Sciences, 3, 112-116. https://doi.org/10.1016/j.cobeha.2015.03.002

Duffy, K. A., \& Chartrand, T. L. (2015b). The Extravert Advantage: How and When Extraverts Build Rapport With Other People. Psychological Science, 26(11), 1795-1802. https://doi.org/10.1177/0956797615600890

Dumont, M., Yzerbyt, V., Wigboldus, D., \& Gordijn, E. H. (2003). Social categorization and fear reactions to the September 11th terrorist attacks. Personality and Social Psychology Bulletin, 29(12), 1509-1520. https://doi.org/10.1177/0146167203256923

Ein-Dor, T., Mikulincer, M., \& Shaver, P. R. (2011). Effective reaction to danger: Attachment insecurities predict behavioral reactions to an experimentally induced threat above and 
beyond general personality traits. Social Psychological and Personality Science, 2(5), 467473. https://doi.org/10.1177/1948550610397843

Farley, S. D. (2014). Nonverbal Reactions to an Attractive Stranger: The Role of Mimicry in Communicating Preferred Social Distance. Journal of Nonverbal Behavior, 38(2), 195-208. https://doi.org/10.1007/s10919-014-0174-4

Fessler, D. M. T., \& Holbrook, C. (2014). Marching into battle: synchronized walking diminishes the conceptualized formidability of an antagonist in men. Biology Letters, 10, 20140592. https://doi.org/http://dx.doi.org/10.1098/rsbl.2014.0592

Fischer, R., \& Karl, J. A. (2019). A primer to (cross-cultural) multi-group invariance testing possibilities in R. Frontiers in Psychology, 10(1507), 1-18. https://doi.org/10.3389/fpsyg.2019.01507

Francois, P., Fujiwara, T., \& Ypersele, T. Van. (2018). The origins of human prosociality: Cultural group selection in the workplace and the laboratory. Science Advances, 4(eaat2201), 1-9. https://doi.org/10.1126/sciadv.aat2201

Gelfand, M. J. (2019). Rule Makers, Rule Breakers: How Tight and Loose Cultures Wire Our World. New York: Scribner.

Gelfand, M. J., Raver, J. L., Nishii, L., Leslie, L. M., Lun, J., Lim, B. C., ... Yamaguchi, S. (2011). Differences between tight and loose cultures: A 33-nation study. Science, 332(6033), 1100-1104. https://doi.org/10.1126/science.1197754

Ginges, J., \& Atran, S. (2011). War as a moral imperative (not just practical politics by other means). Proceedings of the Royal Society B: Biological Sciences, 278(1720), 2930-2938. https://doi.org/10.1098/rspb.2010.2384

Glowacki, L., Isakov, A., Wrangham, R. W., McDermott, R., Fowler, J. H., \& Christakis, N. A. (2016). Formation of raiding parties for intergroup violence is mediated by social network structure. Proceedings of the National Academy of Sciences, 113(43), 12114-12119. https://doi.org/10.1073/pnas.1610961113

Gómez, Á., Brooks, M. L., Buhrmester, M. D., Vázquez, A., Jetten, J., \& Swann Jr, W. B. (2011). On the nature of identity fusion: Insights into the construct and a new measure. 
Journal of Personality and Social Psychology, 100(5), 918.

Gómez, Á., Chinchilla, J., Vázquez, A., López-Rodríguez, L., Paredes, B., \& Martínez, M. (2020). Recent advances, misconceptions, untested assumptions, and future research agenda for identity fusion theory. Social and Personality Psychology Compass, 14(6), 1-15. https://doi.org/10.1111/spc3.12531

Gómez, Á., López-Rodríguez, L., Sheikh, H., Ginges, J., Wilson, L., Waziri, H., ... Atran, S. (2017). The devoted actor's will to fight and the spiritual dimension of human conflict. Nature Human Behaviour. https://doi.org/10.1038/s41562-017-0193-3

Gosling, S. D., Rentfrow, P. J., \& Swann, W. B. (2003). A very brief measure of the Big-Five personality domains. Journal of Research in Personality, 37(6), 504-528. https://doi.org/10.1016/S0092-6566(03)00046-1

Grahe, J. E., \& Bernieri, F. J. (1999). The importance of nonverbal cues in judging rapport. Journal of Nonverbal Behavior, 23(4), 253-268. https://doi.org/10.1023/A:1021698725361

Hasson, U., \& Frith, C. D. (2016). Mirroring and beyond: Coupled dynamics as a generalized framework for modelling social interactions. Philosophical Transactions of the Royal Society B, 371, 20150366. https://doi.org/10.1098/rstb.2015.0366

Hoegl, M., \& Proserpio, L. (2004). Team member proximity and teamwork in innovative projects. Research Policy, 33(8), 1153-1165. https://doi.org/10.1016/j.respol.2004.06.005

Holland, R. W., Roeder, U. R., Van Baaren, R. B., Brandt, A. C., \& Hannover, B. (2004). Don't Stand So Close to Me: The Effects of Self-Construal on Interpersonal Closeness. Psychological Science, 15(4), 237-242. https://doi.org/10.1111/j.0956-7976.2004.00658.x

Jackson, J. C., Jong, J., Bilkey, D., Whitehouse, H., Zollmann, S., McNaughton, C., \& Halberstadt, J. (2018). Synchrony and physiological arousal increase cohesion and cooperation in large naturalistic groups. Scientific Reports, 8(1), 127. https://doi.org/10.1038/s41598-017-18023-4

Karremans, J. C., \& Verwijmeren, T. (2008). Mimicking attractive opposite-sex others: The role of romantic relationship status. Personality and Social Psychology Bulletin, 34(7), 939-950. https://doi.org/10.1177/0146167208316693 
Kim, T., Mcfee, E., Olguin, D. O., Waber, B., \& Pentland, A. S. (2012). Sociometric badges: Using sensor technology to capture new forms of collaboration. Journal of Organizational Behavior, 427(November 2011), 412-427. https://doi.org/10.1002/job

Lafrance, M., \& Broadbent, M. (1976). Group rapport: posture sharing as a nonverbal indicator. Group and Organization Studies, 1(3), 328-333.

Lakin, J. L., \& Chartrand, T. L. (2003). Using nonconscious behavioral mimicry to create affiliation and rapport. Psychological Science, 14(4), 334-339. https://doi.org/10.1111/1467-9280.14481

Lakin, J. L., Jefferis, V. E., Cheng, C. M., \& Chartrand, T. L. (2003). The chameleon effect as social glue: Evidence for the evolutionary significance of nonconscious mimicry. Journal of Nonverbal Behavior, 27(3), 145-163. Retrieved from http://www.springerlink.com/index/R16K6T278246H656.pdf

Lockwood, P. L., Hamonet, M., Zhang, S. H., Ratnavel, A., Salmony, F. U., Husain, M., \& Apps, M. A. J. (2017). Prosocial apathy for helping others when effort is required. Nature Human Behaviour, 1(7), 1-10. https://doi.org/10.1038/s41562-017-0131

Majolo, B., \& Maréchal, L. (2017). Between-group competition elicits within-group cooperation in children. Scientific Reports, 7(srep43277), 1-9. https://doi.org/10.1038/srep43277

McDonald, M. M., Navarrete, C. D., \& Van Vugt, M. (2012). Evolution and the psychology of intergroup conflict: the male warrior hypothesis. Philosophical Transactions of the Royal Society B: Biological Sciences, 367(1589), 670-679. https://doi.org/10.1098/rstb.2011.0301

Muthén, B. O. (1989). Latent variable modeling in heterogeneous populations. Psychometrika, 54(4), 557-585.

Newson, M., Bortolini, T., Buhrmester, M., da Silva, S. R., da Aquino, J. N. Q., \& Whitehouse, H. (2018). Brazil's football warriors: Social bonding and inter-group violence. Evolution and Human Behavior, 39(6), 675-683. https://doi.org/10.1016/j.evolhumbehav.2018.06.010

Olguin Olguin, D. (2011). Sensor-Based Organizational Design and Engineering. Massachusetts Institute of Technology. 
Purzycki, B. G., \& Lang, M. (2019). Identity fusion, outgroup relations, and sacrifice: A crosscultural test. Cognition, 186, 1-6. https://doi.org/10.1016/j.cognition.2019.01.015

R Core Team. (2020). R: A Language and Environment for Statistical Computing. Vienna: R Foundation for Statistical Computing.

Salas, E., Grossman, R., Hughes, A. M., \& Coultas, C. W. (2015). Measuring team cohesion: Observations from the science. Human Factors, 57(3), 365-374. https://doi.org/10.1177/0018720815578267

Schachter, S. (1959). The Psychology of Affiliation: Experimental Studies of the Sources of Gregariousness. Chicago: The University of Chicago Press. https://doi.org/10.2307/1419397

Sosis, R., Kress, H. C., \& Boster, J. S. (2007). Scars for war: Evaluating alternative signaling explanations for cross-cultural variance in ritual costs. Evolution and Human Behavior, 28(4), 234-247. https://doi.org/10.1016/j.evolhumbehav.2007.02.007

Stasser, G., \& Titus, W. (2003). Hidden profiles: A brief history. Psychological Inquiry, 14(February 2015), 304-313. https://doi.org/10.1080/1047840X.2003.9682897

Swann, W. B., Buhrmester, M. D., Gómez, A., Jetten, J., Bastian, B., Vázquez, A., ... Zhang, A. (2014). What makes a group worth dying for? Identity fusion fosters perception of familial ties, promoting self-sacrifice. Journal of Personality and Social Psychology, 106(6), 912926. https://doi.org/10.1037/a0036089

Swann, W. B., Gómez, A., Huici, C., Morales, J. F., \& Hixon, J. G. (2010). Identity fusion and self-sacrifice: arousal as a catalyst of pro-group fighting, dying, and helping behavior. Journal of Personality and Social Psychology, 99(5), 824-841. https://doi.org/10.1037/a0020014

Swann, W. B., Gómez, A., Seyle, D. C., Morales, J. F., \& Huici, C. (2009). Identity fusion: the interplay of personal and social identities in extreme group behavior. Journal of Personality and Social Psychology, 96(5), 995-1011. https://doi.org/10.1037/a0013668

Talhelm, T., Zhang, X., \& Oishi, S. (2018). Moving chairs in Starbucks: Observational studies find rice-wheat cultural differences in daily life in China. Science Advances, 4(4), 1-10. 
https://doi.org/10.1126/sciadv.aap8469

Taylor, S. E. (2006). Tend and befriend: Biobehavioral bases of affiliation under stress. Current Directions in Psychological Science, 15(6), 273-277. https://doi.org/10.1111/j.14678721.2006.00451.x

Tickle-Degnen, L., \& Rosenthal, R. (1990). The nature of rapport and its nonverbal correlates. Psychological Inquiry, 1(4), 285-293.

Tracy, J. L., Randles, D., \& Steckler, C. M. (2015). The nonverbal communication of emotions. Current Opinion in Behavioral Sciences, 3, 25-30. https://doi.org/10.1016/j.cobeha.2015.01.001

Tripathi, P., \& Burleson, W. (2012). Predicting creativity in the wild: Experience sample and sociometric modeling of teams. Proceedings of the ACM Conference on Computer Supported Cooperative Work, CSCW, 1203-1212. https://doi.org/10.1145/2145204.2145386

van Baaren, R. B., Holland, R. W., Kawakami, K., \& van Knippenberg, A. (2004). Mimicry and prosocial behavior. Psychological Science, 15(1), 71-74. https://doi.org/10.1111/j.09637214.2004.01501012.x

Van Vugt, M., De Cremer, D., \& Janssen, D. P. (2007). Gender differences in cooperation and competition. Psychological Science, 18(1), 19-23. https://doi.org/10.1111/j.14679280.2007.01842.x

Vandenberg, R. J., \& Lance, C. E. (2000). A Review and synthesis of the measurement invariance literature: Suggestions, practices, and recommendations for organizational research. Organizational Research Methods, 3(1), 4-69. https://doi.org/10.1177/109442810031002

Voors, M., Nillesen, E., Verwimp, P., Bulte, E., Lensink, R., \& Soest, D. Van. (2012). Violent conflict and behavior: A field experiment in Burundi. American Economic Review, 102(452), 941-964.

Waber, B. N., Aral, S., Olguin Olguin, D., Wu, L., Brynjolfsson, E., \& Pentland, A. (2011). Sociometric badges: A new tool for I.S. research. SSRN Electronic Journal. 
https://doi.org/10.2139/ssrn.1789103

Wann, D. L., Carlson, J. D., \& Schrader, M. P. (1999). The impact of team identification on the hostile and instrumental verbal aggression of sport spectators. Journal of Social Behavior and Personality, 14(2), 279-286.

Whitehouse, H. (2018). Dying for the group: Towards a general theory of extreme self-sacrifice. Behavioral and Brain Sciences, 41, E192. https://doi.org/10.1017/S0140525X18000249

Whitehouse, H., \& Lanman, J. A. (2014). The ties that bind us. Current Anthropology, 55(6), 123. https://doi.org/10.1086/678698

Whitehouse, H., McQuinn, B., Buhrmester, M., \& Swann, B. W. (2014). Brothers in arms: Libyan revolutionaries bond like family. Proceedings of the National Academy of Sciences, (Early edition), 10-12. https://doi.org/10.1073/pnas.1416284111

Whitehouse, Harvey, Jong, J., Buhrmester, M. D., Gómez, Á., Bastian, B., Kavanagh, C. M., ... Gavrilets, S. (2017). The evolution of extreme cooperation via shared dysphoric experiences. Scientific Reports, 7, 44292. https://doi.org/10.1038/srep44292

Xygalatas, D., Khan, S., Lang, M., Kundt, R., Kundtová Klocová, E., Krátký, J., \& Shaver, J. H. (2019). Effects of extreme ritual practices on psychophysiological well-being. Current Anthropology, 60(5), 699-707. https://doi.org/10.1086/705665

Yuki, M., \& Yokota, K. (2009). The primal warrior: Outgroup threat priming enhances intergroup discrimination in men but not women. Journal of Experimental Social Psychology, 45(1), 271-274. https://doi.org/10.1016/j.jesp.2008.08.018

Zhang, Y., Olenick, J., Chang, C.-H., Kozlowski, S., \& Hung, H. (2018). TeamSense: Assessing Personal Affect and Group Cohesion in Small Teams through Dyadic Interaction and Behavior Analysis with Wearable Sensors. Proceedings of the ACM on Interactive, Mobile, Wearable and Ubiquitous Technologies, 2(3), 1-22. https://doi.org/10.1145/3264960 
